\title{
ENZYMATIC ANTIOXIDANT PROTECTION IN PATIENTS WITH MILD COGNITIVE DECLINE AND LATE-ONSET DEPRESSION
}

\section{N. Neznanov}

Federal state budgetary institution «Bekhterev National Medical Research Psychiatry and Neurology Center», Old age psychiatry, St.Petersburg, Russia.

Oxidative stress (OS) is one of the leading pathogenetic factors in the development of neurodegenerative diseases.

The aim of the presented work is to identify the severity of $\mathrm{OS}$ in patients with mild cognitive decline (presumably $A D$ ), with a mild cognitive decline caused by vascular etiology, as well as in patients suffering from depressive disorder, compared with the control group of the same age.

As an evaluation criterion, we chose the activity of key enzymes of antioxidant protection (AOP) - superoxide dismutase (SOD), glutathione peroxidase (GPO) and glutathione reductase (GR). The activity of antioxidant enzymes was determined using standard techniques in the hemolysate of red blood cells of the examined patients.

A comparative analysis of the activity of key AOP enzymes revealed various degrees of disturbance in the activity of the enzymatic AOP of the blood of all examined patients and the impairment of their balance, which is one of the reasons for the increased generation of toxic free radical compounds and the aggravation of the OS condition. The most expressed vulnerability of the glutathione system was found in all the examined groups of patients, especially in those suffering from depression, compared with healthy elderly people.

The revealed decrease in GPO activity was associated with a decrease in the breakdown of peroxide compounds and, in the first place, lipid peroxides.
These changes are especially significant in patients suffering from depression of late age. Thus, the condition of the $\mathrm{OS}$ in the examined patients is aggravated by the most pronounced changes in AOP and, in the first place, the glutathione system, as well as a violation of their balance, which is especially pronounced in patients with late-age depression.
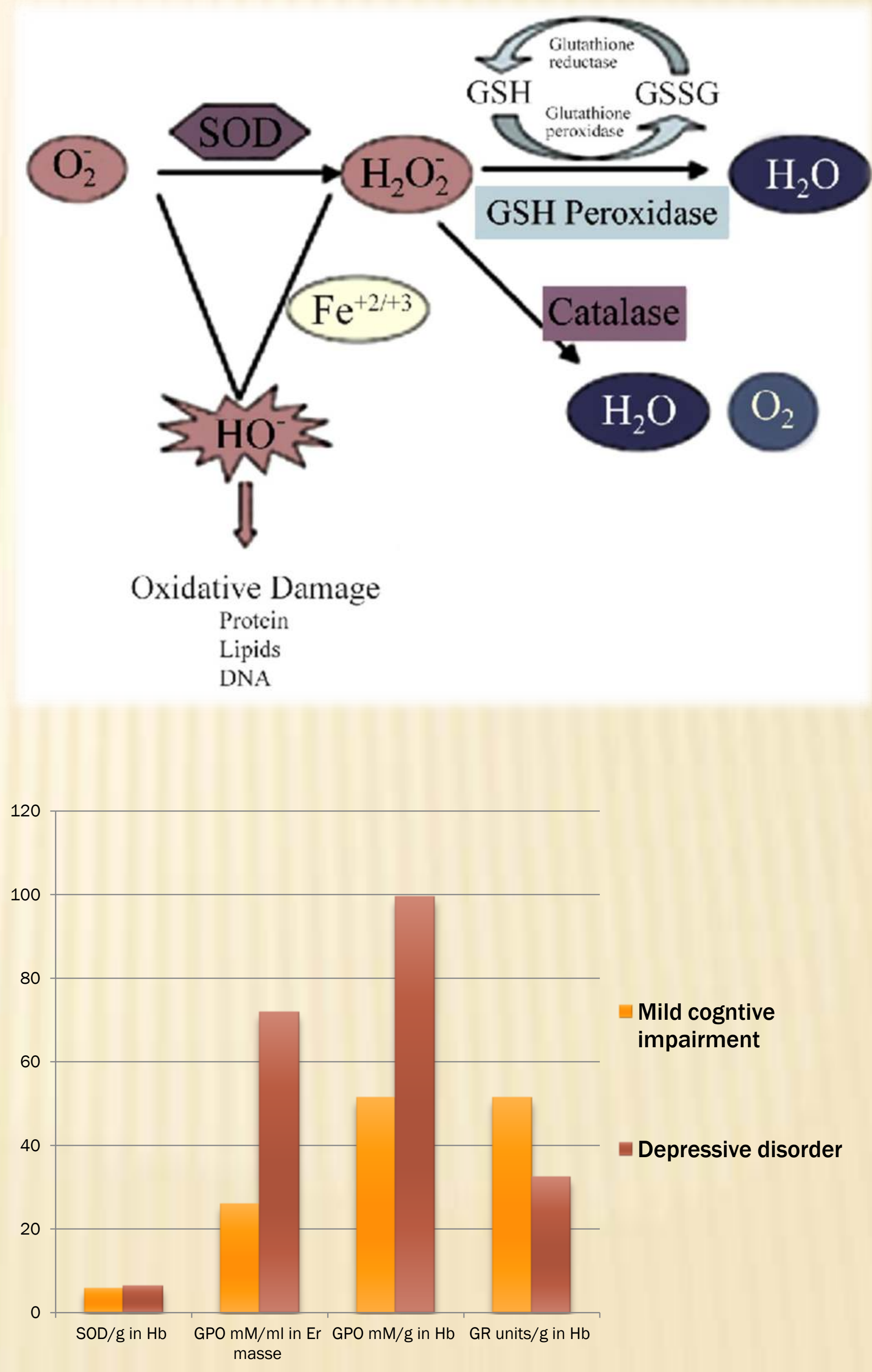